\title{
Interactive comment on "Large scale hydrological model river storage and discharge correction using satellite altimetry-based discharge product" by Charlotte Marie Emery et al.
}

\section{Anonymous Referee \#2}

Received and published: 16 November 2017

Interactive comment on "Large scale hydrological model river storage and discharge correction using satellite altimetry-based discharge product" by Charlotte Marie Emery et al.

This study presents a data assimilation technique based on the Ensemble Kalman Filter, for reducing uncertainties in ISBA-CTRIP land surface model with ENVISAT radar altimeter based discharge data. The authors explored several localization methods during implementation in the Amazon basin, and made a good case, for the effectiveness of using Altimeter data to improve land surface models with the proper approach. I think the research presented here is in line with quality and value to its field that

Printer-friendly version

Discussion paper 
HESS strives to provide for its readers. I do have a few concerns that I feel should be addressed before publication as well as a few minor suggestions. Major comments: 1 . The objectives stated in line 5 and 6 of the abstract and those stated lines $23-24$ of page three are different. In my opinion, the paper demonstrates quite clearly that the assimilation improves results, but actually focuses in the difference between localization methods more than the importance of altimeter data as a source for reducing uncertainties. 2. The description of the altimetry based discharge product section (2.3.1) is quite in depth, however, it should really include a brief statement about QA/QC from the data source's literature. The instrument precision is provided, but the reader has no idea what sort of error that translates to in terms of discharge. 3. Page7 line 30-32 I'm curious what portion of virtual stations were associated with an adjacent cell. 4. Section 2.3.2, this draws further questions about the objective of the study. The authors point out that in situ data was not used in the assimilation. In my opinion, a comparative run with assimilated in situ data could help demonstrate the value of altimeter data, if that is the primary focus. 5. Page 24 lines 13-16, I think this should be clarified to be within topological limitation, (i.e. "should be impacted by all upriver observations"). 6. Page 24 line 19, This manuscript hasn't made a case to support the inclusion of discussion of the groundwater time constant as a major control on discharge. Please include information on this in the results section. 7. Page 24 lines 23-32, I think the authors need to be really careful assigning usefulness of these other altimeter mission for their assimilation protocol. The ENVISAT contemporary missions and those after, are likely to provide data quality that could allow for the construction of additional discharge data, but the casual mention of these missions doesn't really address the feasibility building rating curves and discharge data from them. The biggest issue here is the inclusion of earlier mission, and the citation provided. To my knowledge there has been only marginal success using pre-ENVISAT data on rivers. Using ERS 1-2 or TOPEX would most likely only work on the main channel if at all. In Tourian et al., 2017, the authors specifically mention that these earlier mission were not included because of poor inland performance. Minor comments: 1. Page 6 line 23, crosses the

Printer-friendly version

Discussion paper 
river stream is redundant. 2. Page 23 line 2 "to correct directly the discharge" should be to directly correct the discharge. I think all of the clarifications and changes I have recommended are relatively minor. With a few changes, I will recommend accepting this paper for publication.

Interactive comment on Hydrol. Earth Syst. Sci. Discuss., https://doi.org/10.5194/hess-2017516, 2017. 